\title{
Erratum
}

\section{An internally consistent model for the thermodynamic properties of $\mathrm{Fe}-\mathrm{Mg}$-titanomagnetite-aluminate spinels}

\author{
Richard O. Sack ${ }^{1}$ and Mark S. Ghiorso ${ }^{2}$ \\ ${ }^{1}$ Department Earth and Atmospheric Sciences, Purdue University, West Lafayette, IN 47907, USA \\ ${ }^{2}$ Department Geological Sciences, AJ-20, University of Washington, Seattle, WA 98195, USA \\ Contrib Mineral Petrol (1991) 106:474-505
}

An unfortunate error occured in Eqs. ( $3 a)$ and $(3 b)$ on p. 476 of the above article.

A factor of one-half was omitted in both equations, which should have read as follows:

$s_{2}=\frac{1}{2}\left[2 X_{\mathrm{A} 1^{3+}}^{\mathrm{oct}}-X_{\mathrm{A} 1^{3+}}^{\mathrm{tet}}\right]$

$s_{4}=\frac{1}{2}\left[2 X_{\mathrm{Fe}^{3}}^{\mathrm{oct}}-X_{\mathrm{Fe}^{3+}}^{\mathrm{tet}}\right]$. 